\title{
Application of innovative technology "Media Synergy" in the process of training specialists at the technical university in the conditions of digitalization of education
}

\author{
Tatiana Vlasova ${ }^{1,{ }^{*}}$ and Evgenia Krasnova ${ }^{1}$ \\ ${ }^{1}$ Don State Technical University, 1, Gagarina, sq., 344003, Rostov-on-Don, Russia
}

\begin{abstract}
The article is devoted to the innovative technology of upbringing students "Media synergy", which was used for four years of training teachers at the technical University in a prolonged experiment. Special attention is paid to the analysis of educational technologies that are used in higher foreign and domestic professional education, including information, health-saving, subject, media, upbringing, in the conditions of digitalization of all spheres of life in modern society. The article substantiates a set of conceptual ideas that allowed us to determine the criteria of the spiritual and ethical component of the existential period of students. Models of the "Media synergy" technology were developed; the results of the application of innovative technology were summarized, which allowed to realize the main goal in the professional education of teachers - to overcome the pseudo-virtual picture of the world in the minds of students through synergetic relationships between equal partners and through interaction based on anti-manipulative techniques in the media space.
\end{abstract}

\section{Introduction}

The relevance of the research is due to the fact that in the conditions of digitalization of education (contactless learning), personal communication between teachers and students has significantly decreased, and, consequently, trust, which is the main attribute of spiritual and ethical influence on young people, has decreased. On the other hand, in the twenty-first century, it makes no sense to give up the advantages of information and communication culture, which allows you to expand not only the personal horizons of a person, but also the socio-economic prospects of society. At the same time, the full - scale immersion of students in the virtual educational space - distance learning in the first half of 2020 in the context of a pandemic-requires teachers to implement innovative educational technologies that can limit the emerging multimedia risks. The authors of this article justified the model of overcoming these risks [1], which was tested at an International scientific conference (2019), which allowed reducing multimedia challenges, including: 1) reduce the pressure of

\footnotetext{
${ }^{*}$ Corresponding author: tvlasova@rambler.ru
} 
virtual reality on the construction of production (service) space and its distortion in the conditions of a technical University, 2) reduce the spiritual impact of media fakes on future specialists. In parallel, starting in 2015, the technical University implemented a prolonged experiment on the introduction of innovative technology "Media synergy" [2] throughout the full cycle of training of bachelors - future teachers, which led to a reduction in the spiritual and ethical risks of global digitalization of higher education. During this experiment, the effectiveness of the chosen spiritual ontological methodology was also proved, on the basis of which the application of innovative upbringing technology through the organization of social partnership was based.

The relevance of this research is also due to the fact that the Russian pedagogical science does not sufficiently develop the issues of upbringing and upbringing technologies in higher education. For example, when requesting an electronic scientific library (eLIBRARY.RU) the following figures were issued: the total number of scientific articles on educational technologies in higher education was 3,958; and the total number of articles on student upbringing was only 236 (accessed 02.07.2020). Analysis of the latter has shown that they usually translate traditional approaches that, on the one hand, demonstrate the "correctness" of the target settings, such as: the upbringing of citizenship, or patriotism, or morality of students; on the other hand, they offer very formal methods of upbringing. It becomes obvious that there is a need to return upbringing issues to the sphere of scientific discourse and the practice of professional education. Analysis of the content of articles showed that only individual authors (M. Anghela, 2014, V. Abraukhova, 2020, B.A. Voronin, 2020) focus the attention of the pedagogical community on upbringing problems, justifying innovative ways to solve them $[3,4,5]$. A number of scientists (V. Cherenkov, N. Cherenkova, 2018; N. Iivari, S. Sharma, L. Ventä-Olkkonen, 2020) also suggest restoring the upbringing function in higher education, for example, through the geopolitical socialization of students [6].

At the same time, the absolute majority of domestic and foreign scientists do not justify and do not take into account the spiritual sphere of students, which must be "involved" in the process of training specialists, which causes unique harm to both the personal development of students and their professional development. The logic of this research suggests the need to analyze foreign and domestic works on educational technologies that are used in the field of modern higher education.

\section{Review of scientific sources}

We will present an overview of scientific sources in the Russian Humanities on separate blocks and problems. The first of them: information technologies from the perspective of cyber education and digitalization of all spheres of life in modern society (R.G. Bolbakov, 2015; V. Ya. Tsvetkov, 2017; E. Fleaca, A. Mar in, R.D. Stanciu, 2016, 2019) [7, 8]. The second is multimedia technologies in professional education (V. Abraukhova, N. Safontseva, 2018) [9]. The third is spiritual and moral technologies based on the synthesis of science and religion, which are used in the process of professional training of specialists at the University (A.V. Korzhuev, T. Vlasova, 2020) [2]. These aspects show the hierarchy of educational technologies, their interdependence and focus on the development of students' personality and the education system as a whole.

So, V. Ya. Tsvetkov based cyber technologies on integration and developed cognitive structures for intelligent management. On the basis of cyberphysical systems` ideology, the scientist proposed to connect these objects, which created a synergistic effect, becoming, in turn, analogous "to an open" neural network. Information technologies are therefore subject to changes due to the introduction of new models and Internet communications, programs and platforms, which, in turn, also depend on the cyber equipment of a particular level of 
education. Regarding the introduction of cyber technologies in professional education, it should be pointed out that all of the above are objective conditions. And the "human factor" can be attributed to the subjective factors of negative connotation due to the fact that most teachers do not have time to master the latest cyber technologies, as evidenced by a number of scientific studies (E. Tițan, A. Burciu, D. Manea, A. Ardelean, 2014) [10].

A new stage in the development of cyber technologies in professional education is associated with multimedia technologies, which are analyzed in detail by the scientist R. G. Bolbakov. The first period, in his opinion, initially refers to the appearance of multimedia products in the consumer sphere. In education, this was used only as auxiliary forms, such as in the form of audio and video classes. Gradually, information technologies began to absorb the full range of paralinguistic capabilities, and multimedia education appeared as an independent phenomenon. According to R. G. Bolbakov, in the modern development of civilization, there are at least ten reasons for this symbiosis: cyber technologies and the overall picture of the world, because its formation in students depends primarily on the learning system. The process of professional formation should be based on large information flows when creating various models, which changes the content of the reflective activity of students consciousness, thus leading to the appearance of a new picture of reality in the cognitive space of a person.

Returning to the idea of V. Ya. Tsvetkov, we can conclude that the synergistic effect arising from the interaction of virtual (media) and neural systems becomes a real phenomenon through multimedia educational technologies. These realities were studied much earlier in developed foreign countries. So a number of scientists (N. Luman, 2000; G. Morrison, 2010) [11] drew attention to this component of human interaction, which began to spread to different levels of education [12]. In the discourse on innovations in professional education, we have studied the works of such scientists as: A. Perez, A. Potocki, I. Ivanova, J. Cárdenas Cobob, M. Kosonogova which thoroughly justified the new generation of educational technologies based on cognitive connections and psychological mechanisms, as well as a tool for training teachers $[13,14]$. Similar processes in the organization of education based on innovative cyber technologies can be observed both in European countries [15] and in the South-Eastern region of the world, as well as in the system of higher professional education in the Russian Federation [16].

At the same time, it should be clarified that these cyber technologies are used exclusively within the framework of training (as subject or health-saving) and do not affect upbringing aspects at all. Further discourse is related to the analysis of multimedia technologies in the field of upbringing in Russian education. Based on the targets set by the national project "Education" in 2018, the Russian Federation should create conditions "...for the introduction by 2024 of a modern and secure digital educational environment that ensures the formation of values for self-development and self-education among students of educational organizations of all types and levels, by updating the information and communication infrastructure, training personnel, and creating a Federal digital platform" (Russian Standard). We see that digitalization of training of pedagogical (teaching) personnel is becoming a state task for the University level, including upbringing issues as the basic for the development of modern Russia. The authors of the article conducted an experiment on the spiritual and ethical development of students at a technical University who receive a specialty - teacher, trainer, tutor, that is, an employee in the field of education. In the next section, we will describe the methods of this research and the stages of the pedagogical experiment.

\section{Methods of research}


When organizing the extended study, we relied on a systematic approach that allowed us to draw up a project and program of the experiment. We used theoretical and practical methods: analysis and synthesis of scientific concepts; comparative experiment, extended experiment on the same sample of respondents-students; observation and questioning of students, structural and functional analysis of the results. The experiment included the following stages: theoretical and conceptual, diagnostic and prognostic, upbringing and developmental, control and effective. In 2015, two groups were selected of the first year students (bachelor's degree), in which training was conducted in the pedagogical direction: one - an experimental group at the technical University, Rostov-on-Don; the other - a control group at the branch of the University of Economics, Taganrog. Each group had the same number of respondents ( 24 people) at the diagnostic stage. During the experiment, the number of students varied for objective reasons. The average number of respondents was 20 in each group. In these groups, four disciplines of pedagogical content were read, which were included in the experiment program (one academic discipline in each academic year). At the same time, the independent variable in the experiment was the technology "Media synergy", which was implemented in the experimental group. In the control group, the teaching of these pedagogical disciplines was carried out on a traditional basis. Dependent variables in both the experimental and control groups were indicators of the spiritual and ethical picture of the world in students. In 2019, the results were analyzed, and in 2020, a scientific article was published.

\section{Results and discussion}

Theoretical and conceptual stage of research. We have proved a set of ideas that allowed us to focus the attention of teachers on the upbringing aspect of professional training. In this process, realizing the educational function, teachers can rely on spiritually developing technologies, such as: " Ontological pluralism", " Conflict-Free religious tolerance", " Media synergy", "Moral co-operation". At the same time, the main goal of spiritually developing technologies is expediently organized equal interaction that actualizes the concrete existence of participants, activating their real sense of life as a good. It should be remembered that in the conditions of total cyberdigitalization, students experience a violation of this feeling, since the coherence of processes reduces the threshold of critical thinking, at least. In addition, images and pictures of the virtual world that exist only in the imagination are fixed at the communication and media level, which leads to the consolidation of myths. On the one hand, this can lead to unprofessional actions; on the other hand, it can lead to the denial of life itself. The authors of the article describe this phenomenon as a "cognitive paradox" [1], that is, the student, due to his existential period of life, feels the fullness of his own powers, but his immersion in the virtuality (media of being) destroys the belief in the truth of the facts of this being. Therefore, it is advisable to use, first of all, the potential of the spiritual-developing technology "Media synergy" as an upbringing tool for the professional development of future teachers in every interaction with students. The delayed result of this influence will be their readiness to use this technology in future teaching activities.

Thus, we have identified a basic indicator of the spiritual and cognitive component of the student's personality: the ability of the mind to distinguish between real facts and their virtual counterparts with a qualitative definition of their professionally and ethically significant content.

Diagnostic and prognostic stage of the study. At the stage of input diagnostics (2015), we defined two criteria: getting pleasure through virtual reality (six questions in the questionnaire) and the degree of critical thinking in virtual space (six questions in the questionnaire). Two groups of students were surveyed on the following questions: 1) I like 
to communicate with friends via social networks; 2) I like to get information from the Internet; 3) I like to hang out on the Internet in my free time; 4) I like to play media games; 5) I like to watch movies only on the Internet; 6) I prefer to read books on the Internet; 7) I like to play computer games; 8) I like to virtually travel the Internet; 9) I like to take selfies (my own photo) in any situations; 10) I prefer to play dangerous quests (story games). 11) I trust media information related to other people; 12) I trust country-specific media information. As a result of the analysis of data on input diagnostics, it was concluded that both groups of students have identical indicators, located in the same numerical category. So, the average indicators for both groups are as follows: "getting pleasure through virtual reality" is $77 \%$; "the degree of critical thinking in virtual space" is $23 \%$. Prognostically, the task was set to activate the work to increase the degree of critical thinking, since this can lead to the education of students of the spiritual and ethical component of the analysis of media information, at least.

Upbringing and developmental stage of the research. For four years, the experimental group used the innovative technology "Media synergy" at each lesson in pedagogy, the main content of which is the postulate: truth is not one - dimensional, so in network interaction, honest information and its spiritual and moral interpretation are valuable. At the same time, the teacher paid special attention to the specifics of the existential period of a young person (from 17 to 27 years). A, namely: 1) the spiritual indicator "feeling of life as a good" during this period dominates the cognitive sphere of life; 2) the so-called "test of life", that is, the confirming aspect of this feeling is in the sexual sphere of life of a young person (receiving pleasure of any form); 3) and the developing aspect of this feeling is concentrated in the moral sphere of life. Thus, all dialogues around any subject of the academic subject were conducted based on the specifics of the existential period of students, on the one hand, and on the other, based on the designated postulate concerning the truth from the innovative technology "Media synergy". Figure 1 shows the dependence of the pedagogical goal on the algorithm of students 'activity based on the technology "Media synergy".

\section{The GOAL is to overcome the pseudo virtual picture of the world} Algorithm for tracking activity

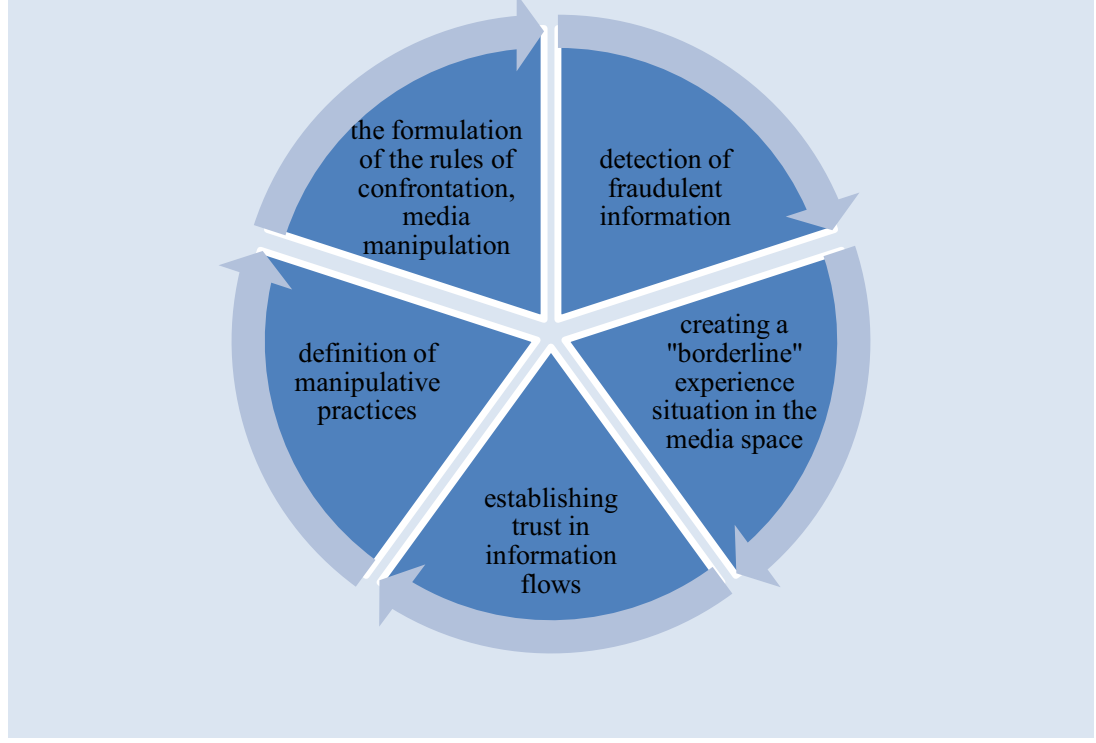

Fig. 1. "Media synergy" Technology based on the thinking activity algorithm 
The control and effective stage of the experiment was to, first, compare the forms of activity: traditional and multimedia (figure 2), and secondly, to analyze the data obtained during the final survey of students in the experimental and control groups.

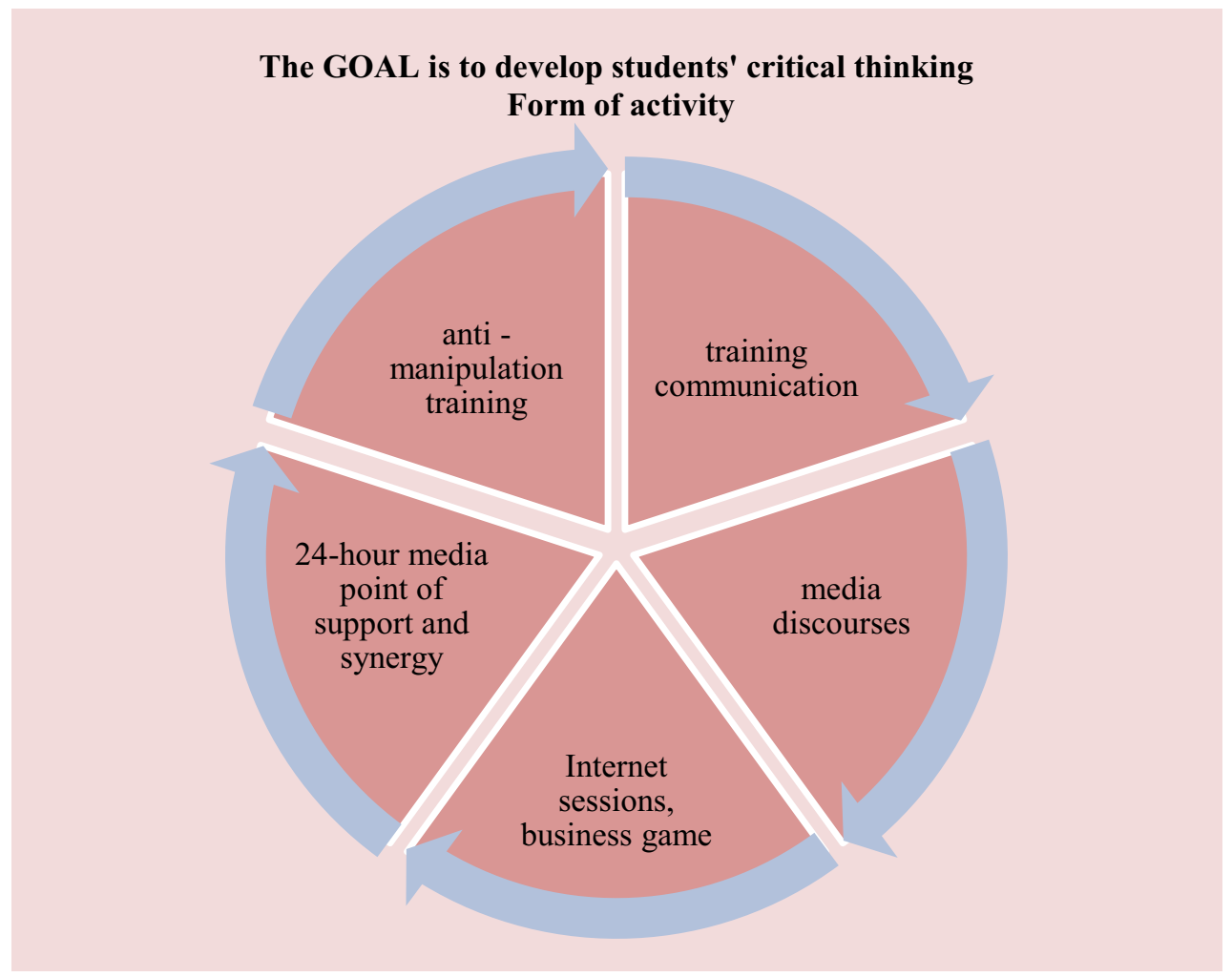

Fig. 2. Technology "Media synergy" by forms of educational activity

At the end of the study, the following results were obtained (table 1):

Table 1. Comparative results matrix

\begin{tabular}{|l|c|c|c|c|}
\hline & \multicolumn{3}{|c|}{ Criteria for the spiritual and ethical picture of the world in the minds of students } \\
\hline group & \multicolumn{2}{|c|}{$\begin{array}{c}\text { the pursuit of pleasure through virtual } \\
\text { reality }\end{array}$} & \multicolumn{2}{c|}{$\begin{array}{c}\text { the degree of critical thinking in the } \\
\text { virtual space }\end{array}$} \\
\hline & $\%, 2015$ & $\%, 2019$ & $\%, 2015$ & $\%, 2019$ \\
\hline experimental & 78 & 36 & 22 & 64 \\
\hline control & 76 & 88 & 24 & 12 \\
\hline
\end{tabular}

Judging by the percentage of the above criteria, students in the experimental group began to treat media information more meaningfully, process it critically, and emotionally select those experiences that initially orient them to the ethical and moral aspects of real facts. At the same time, the cognitive aspect of their existential period was more stable compared to the students in the control group. Experimentally, we confirmed the conclusion that students were able to overcome distrust of the adult world through a synergistic relationship between students and teachers, as between equal partners. 


\section{Conclusions}

The research allowed the authors of the article:

1. Develop models of innovative technology "Media synergy".

2. To substantiate the indicator of the spiritual and cognitive component of students' personality, defining its content as the ability of consciousness to distinguish between real facts and their virtual counterparts with a qualitative definition of their professionally and ethically significant content.

3. Introduce upbringing technology in the process of training teachers at the technical University.

\section{References}

1. T. Vlasova, V. Abraukhova, N. Mamchits, E. Egorova, SHS Web of Conferences, 70, 03006 (2019) doi: 10.1051/shsconf/20197003006

2. A. V. Korzhuev, T. Vlasova, V. Sinyachkin, V. V. Vorozhikhin, N. E. Sudakova XLinguae, 13(3), 78-93 (2020) DOI: 10.18355/XL.2020.13.03.08

3. M. Anghela, PrSBS, 142, 19-23 (2014)

4. T. Vlasova, V. Abraukhova, E. Krasnova, E3S Web of Conferences, 175, 15010 (2020) doi.org/10.1051/e3sconf/202017515010

5. B. A. Voronin, I. P. Chupina, Ya. V. Voronina, Yu. N. Chupin, E. V. Zarubina, N. N. Simachkova, E3S Web of Conferences, 176, 05016 (2020) doi.org/10.1051/e3sconf /202017605016

6. N. Iivari, S. Sharma, L. Ventä-Olkkonen, IJofIM, 15, 1-6 (2020) doi.org/10.1016 /j.ijinfomgt.2020.102183

7. E. Fleacă, A. Marin, B. Fleacă, The challenges of Romanian higher education - a review on key enablers for modernization, Pr.T., 22, 1121 -1128 (2016)

8. E. Fleaca, R. D. Stanciu, PrM, 32, 1051-1057 (2019)

9. T. Vlasova, E. Krasnova, V. Abraukhova, N. Safontseva, Journal of Social Studies Education Research, 9(1), 76-88 (2018)

10. E. Tițan, A. Burciu, D. Manea, A. Ardelean, Pr.Ec.and F, 10, 269-274 (2014)

11. G. Morrison, S. Ross, J. Kemp \& H. Kalman Designing effective instruction: Applications of instructional design (New York, NY: Wiley, 2010)

12. A. Gutnick, M. Robb, L. Takeuchi \& J. Kotler Always Connected: The New Digital Media Habits of Young Children. (New York, 2011) www.ictliteracy.Info /rf.pdf/jgcc alwaysconnected.pdf

13. A. Perez, A. Potocki, M. Stadtler, M. Macedo-Rouet, J. Paul, L. Salmerón, \& J. Rouet, Learning and Instruction, 58, 53-64 (2018). doi.org/10.1016/j.learninstruc. 2018.04.006.

14. I. Ivanova, J. Cárdenas Cobob, M. Kosonogova, Pr.CS, 172, 517-522 (2020)

15. G. Klinkov, M. Rodionov, N. Bakharev, E. Vezetiu, E. Vovk, AMAZONIA INVESTIGA, 9(26), (2020)

16. N. Gafiatulina, L. Makadey, I. Gluzman, A. Lozhechkina, L.Volkova, A. Bandurin, EurAsian Journal of BioSciences, 13(2), 1557-1563 (2019) 